JASEM ISSN 1119-8362

All rights reserved
Full-text Available Online at www.bioline.org.br/ja
J. Appl. Sci. Environ. Mgt. June, 2006

Vol. 10 (2) 49 - 53

\title{
Removal of COD and Colour from Sanitary Landfill Leachate by using Coagulation - Fenton's Process
}

\author{
AMUDA, O S \\ Department of Pure and Applied Chemistry, Ladoke Akintola University of Technology, Ogbomoso, 210001, Nigeria. Tel: 2348034402907 \\ E-mail: omotayosharafdeen@yahoo.com
}

\begin{abstract}
This study investigated two methods for the removal of COD and colour from sanitary landfill leachates. The first method involved the use of coagulation/flocculation process using $\mathrm{FeCl}_{3}$ as a conventional coagulant and $\mathrm{Ca}(\mathrm{OH})_{2}$ as base-precipitant. The second method involved integration of Fenton's reagent into the coagulation/flocculation process. Concentration of $\mathrm{FeCl}_{3}$ that reduced chemical oxygen demand (COD), and color by 37 and $62 \%$ is $1000 \mathrm{mg} / \mathrm{l}$. Fenton-coagulation flocculation process reduced the COD and color of the leachates by 88 and $98 \%$ respectively. The optimum conditions for the effectiveness of Fenton's reagent, namely temperature, $\mathrm{pH}, \mathrm{H}_{2} \mathrm{O}_{2}$ and coagulant dose were studied. @JASEM
\end{abstract}

Landfill leachate from municipal solid waste landfill sites are often defined as hazardous and heavily polluted wastewaters. The leachates may contain a large amount of organic matter (both biodegradable and biorefractory carbon), ammonia-nitrogen, heavy metals, chlorinated organic and inorganic salts (Wang et al., 2002). The discharge of landfill leachate can lead to serious environmental problems as they may percolate through soils and sub soils, causing extensive pollution of ground and surface waters if they are not properly treated and safely disposed (Tatsi et al., 2003). Landfill leachate treatment by several methods namely coagulation - flocculation (Tatsi et al., 2003; Amokrane et al., 1997); coagulation - photo oxidation (Wang et al; 2002); nanofiltration (Marttinen et. al, 2002); biological treatment and combined physico-chemicalnanofiltration process (Treboutet, et al. 2001) have been reported. $\mathrm{FeCl}_{3}$ is a widely used coagulant and it has been used for the removal of organic matter in landfill leachates (Tatsi et al., 2003) and industrial wastewater (Peres et al., 2004; Amoo et al., 2004).

Fenton's reagent (hydrogen peroxide in the presence of a ferrous salt) has been used for the treatment of both organic and inorganic substances under laboratory conditions as well as real effluents from different resources like chemical manufacturers, refinery and fuel terminals, engine and metal cleaning etc. (Gogate and pandit, 2004). The process is based on the formation of reactive oxidizing species, able to efficiently degrade the pollutants of the wastewater stream (Bossman et al., 1998; Pignatello et al., 1999). In the oxidation system, three reactive species are involved; two of them involve the presence of hydroxyl radicals (classical Fenton's chemistry) in either 'free' or 'caged' form, whereas third oxidant has been postulated to be aquo or organo-complexes of the high valence iron, the ferryl ion (Gogate and Pandit, 2004). The oxidation system can be effectively used for the destruction of toxic wastes and non-biodegradable effluents to render them more suitable for a secondary biological treatment (Perez et al., 2002 Martinez et al., 2003; Peres et al., 2004).

Therefore, in the first phase of the present work, a coagulation/flocculation method is applied for COD and color removals from the landfill leachate, whereas, the second phase involves coagulation Fenton process for COD and color removal from the landfill leachate. The specific aim of this work was to study the relative effects of different operational schemes such as temperature, $\mathrm{pH}$ value, concentration of $\mathrm{H}_{2} \mathrm{O}_{2}$ and coagulant dose.

\section{MATERIALS AND METHODS}

Leachate sampling: The leachate was collected from Aboru Landfill site (Lagos, Nigeria). Characteristics of the leachate sample are as shown in Table 1.

Table 1. Characteristics of landfill leachate sam
\begin{tabular}{lc}
\hline $\mathrm{pH}$ & 7.9 \\
\hline Conductivity $\left(\mu \mathrm{scm}^{-1}\right)$ & 27.2 \\
BODs $(\mathrm{mg} / \mathrm{l})$ & 2560 \\
COD $(\mathrm{mg} / \mathrm{l})$ & 5420 \\
Color $(\mathrm{pt}$ unit Co) & 6900 \\
Turbidity (NTU) & 315 \\
TDS (g/l) & 15.2 \\
TSS (g/l) & 0.76 \\
\hline
\end{tabular}

Sample analyses: $\quad$ The samples were taken to the laboratory in sealed plastic barrels, stored at $-4^{\mathrm{O}} \mathrm{C}$ before analyses. The initial $\mathrm{pH}$ of the sample was determined by a $\mathrm{pH}$ meter, the COD and color were 
determined following standard methods for the examination of water and wastewater (APHA AWWA-WEF, 1995).

\section{EXPERIMENTAL PROCEDURES}

Effect of coagulant dose on coagulation: Different concentrations such 100, 250, 500, 750 or $1000 \mathrm{mg}$ $\mathrm{FeCl}_{3}$ was added to a $1000 \mathrm{ml}$ leachate sample. After rapid mixing for $5 \mathrm{~min}$ at $200 \mathrm{rpm}$ and slow mixing for $55 \mathrm{~min}$ at $60 \mathrm{rpm}$, the sample was withdrawn by using a plastic syringe from a point about $2 \mathrm{~cm}$ below the top of liquid level at the beaker in order to determine the COD and color, so that the effect of coagulant dose on coagulation could be studied. For the purpose of coagulation, $\mathrm{pH}$ was adjusted to 8.5 by addition of $\mathrm{Ca}(\mathrm{OH})_{2}$.

Effect of hydrogen peroxide dosage on the coagulation - Fenton process: In the FentonCoagulation/flocculation experiment, a dose of $\mathrm{H}_{2} \mathrm{O}_{2}$ ( 0.1 to $2 \mathrm{M}$ ) was added to coagulation - flocculation process in glass reactors, after $120 \mathrm{~min}$, supernatant was sampled to determine COD and color, so that effect of different dose of $\mathrm{H}_{2} \mathrm{O}_{2}$ could be studied.

Effect of temperature on the coagulation - Fenton process: Temperature was varied among 25,35, 40, 45 and $50^{\circ} \mathrm{C}$ in glass reactor after addition of $\mathrm{H}_{2} \mathrm{O}_{2}$. After $120 \mathrm{~min}$, supernatant is sampled to determine COD and color so that effect of temperature on the treatment could be studied.

Effect of ph on the efficiency of coagulation-Fenton process: $\mathrm{pH}$ was adjusted (2.5, 3, 4 and 5) after addition of $\mathrm{H}_{2} \mathrm{O}_{2}$. After $120 \mathrm{~min}$, supernatant is sampled to determine COD and color, so that effect of $\mathrm{pH}$ on the treatment could be studied.

\section{RESULTS AND DISCUSSION}

Effect of coagulant dose on coagulation: The effect of different doses of $\mathrm{FeCl}_{3}$ on the removal of COD and color by coagulation is shown in Fig. 1.

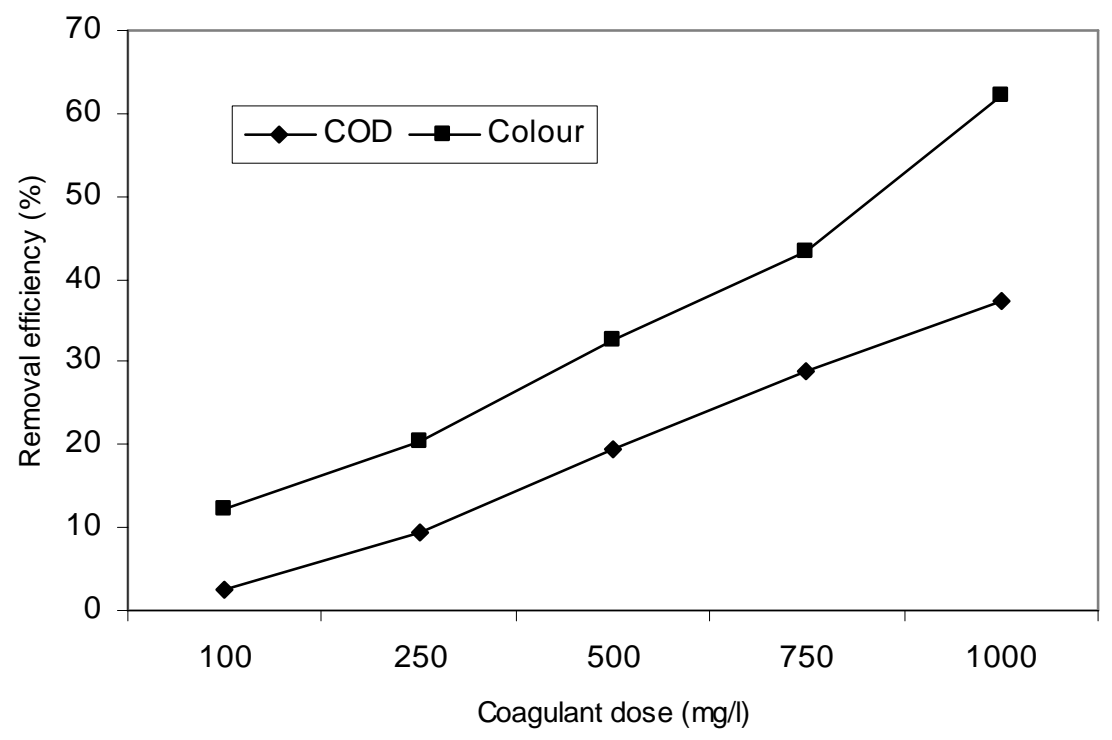

Fig. 1: Effect of coagulant dose on the removal of COD and colour in the leachate

The removal of COD and color increased with increasing concentration of $\mathrm{FeCl}_{3}$. The highest values (37 and 62\%) of COD and color respectively were obtained using a $\mathrm{Fe}^{3+}$ dosage of $1000 \mathrm{mg} / \mathrm{l}$.
Effect of hydrogen peroxide dosage on the coagulation - fenton process: The effect of $\mathrm{H}_{2} \mathrm{O}_{2}$ on the removal of COD and color during coagulationFenton process is as shown in Fig. 2. 


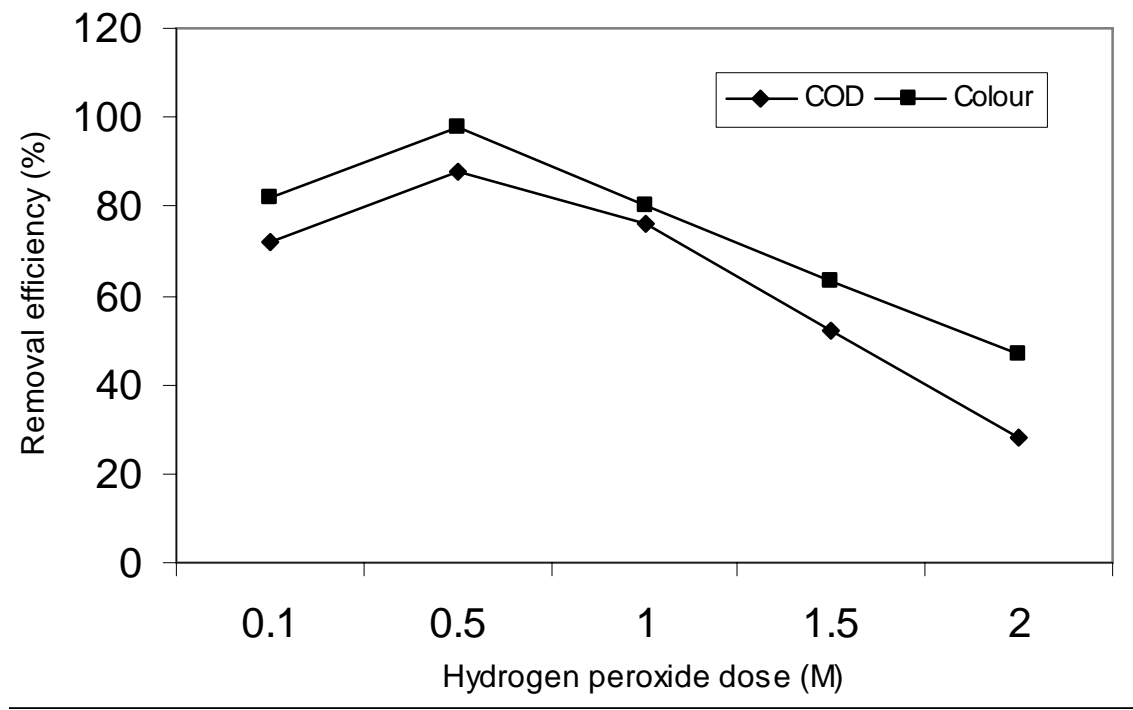

Fig. 2: Effect of $\mathrm{H}_{2} \mathrm{O}_{2}$ dosage on coagulant-Fenton process for the removal of COD and color in the leachate

The dosage of $\mathrm{H}_{2} \mathrm{O}_{2}$ was varied among $0.1,0.5$, 1.0, 1.5 and $2 \mathrm{M}$, increasing the dosage of $\mathrm{H}_{2} \mathrm{O}_{2}$ from 0.1 to $0.5 \mathrm{M}$ increases the enhancement of removal of COD and color in the leachate sample; this finding is in line with the reports of Lin et al., 1999; Kang and Hwang 2000. However, at greater than or equal to 1.0 $\mathrm{M}$ dosage of $\mathrm{H}_{2} \mathrm{O}_{2}$, the removal efficiency of COD reduced. Residual $\mathrm{H}_{2} \mathrm{O}_{2}$ may have contributed to COD. It can be concluded at this point that the dosage of $\mathrm{H}_{2} \mathrm{O}_{2}$ that enhances coagulation-Fenton process is in the range of 0.1 to $0.5 \mathrm{M}$. Higher dosage of $\mathrm{H}_{2} \mathrm{O}_{2}$ may be harmful to microorganisms thus, creating problem to overall degradation efficiency in the subsequent biological treatment .

Effect of $\mathrm{pH}$ on the efficiency of coagulation-Fenton process: $\mathrm{pH}$ has been observed to significantly affect degradation of COD and reduction of color. Others (Lin and Lo, 1997; Kang and Wang 2000) observed similar results. The effect of $\mathrm{pH}$ on the removal of COD and color is as shown in Fig. 3.

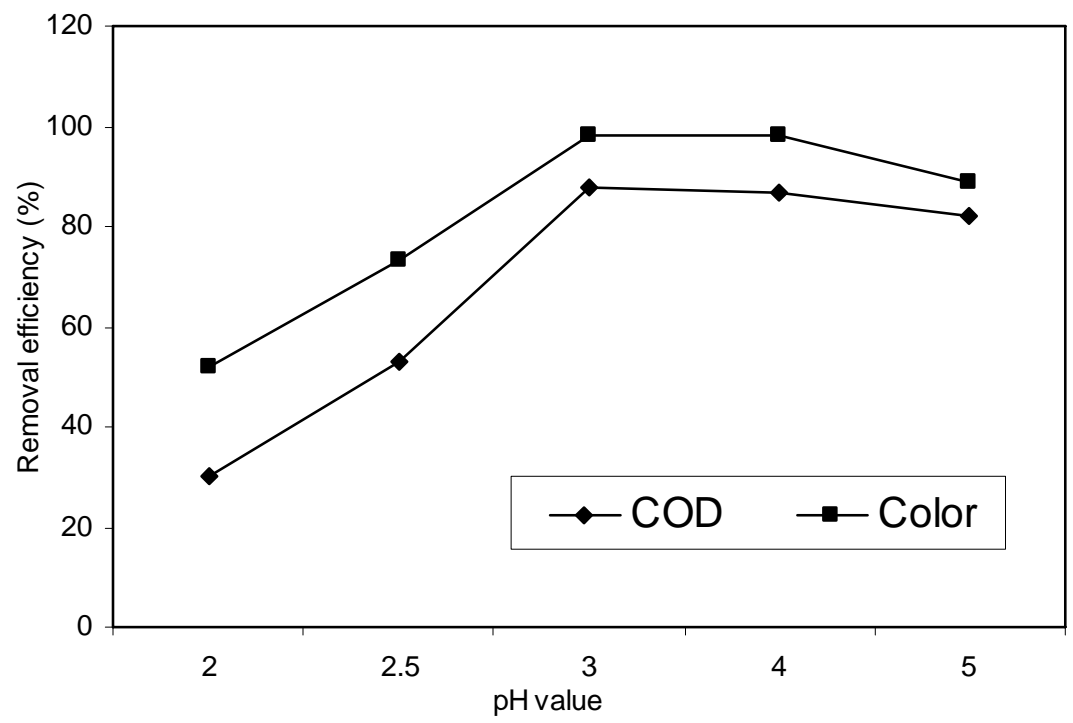

Fig.3: Effect of pH on the efficacy of coagulation - fenton process for the removal of COD and Color in the leachate

The $\mathrm{pH}$ of the system was varied among 2, 2.5, 3, 4 and 5 . In the present work, the recommended $\mathrm{pH}$ for this system is in the range 2.5 to 4 . At $\mathrm{pH}<2.5$ there was reduction in the removal efficiency of COD. This may be due to the formation of $\mathrm{Fe}$ (II) complex which reacts more slowly with $\mathrm{H}_{2} \mathrm{O}_{2}$ and this, 
produces fewer amounts of hydroxyl radicals thereby reducing the efficiency of the process. At $\mathrm{pH}>4$, the removal efficiency also reduced this may be due to decrease of the free iron species in the reacting system which in turn may be due to formation of Fe (II) complex. Kwon et al., (1999) reported decrease in the oxidation potential of $\mathrm{HO}$ radical with an increase in the $\mathrm{pH}$.

Effect of temperature on coagulation-Fenton's process: Temperature only enhanced the removal of
COD very slightly and as such its effect was neglected in all the experiments.

Sequel to this, temperature does not need to be considered in the optimization of Fenton's reaction for the treatment of the leachate studied.

Effect of $\mathrm{fecl}_{3}$ on the coagulation-Fenton process: The effect of different dosages of $\mathrm{FeCl}_{3}$ on the coagulation-Fenton process is shown in Fig. 4.

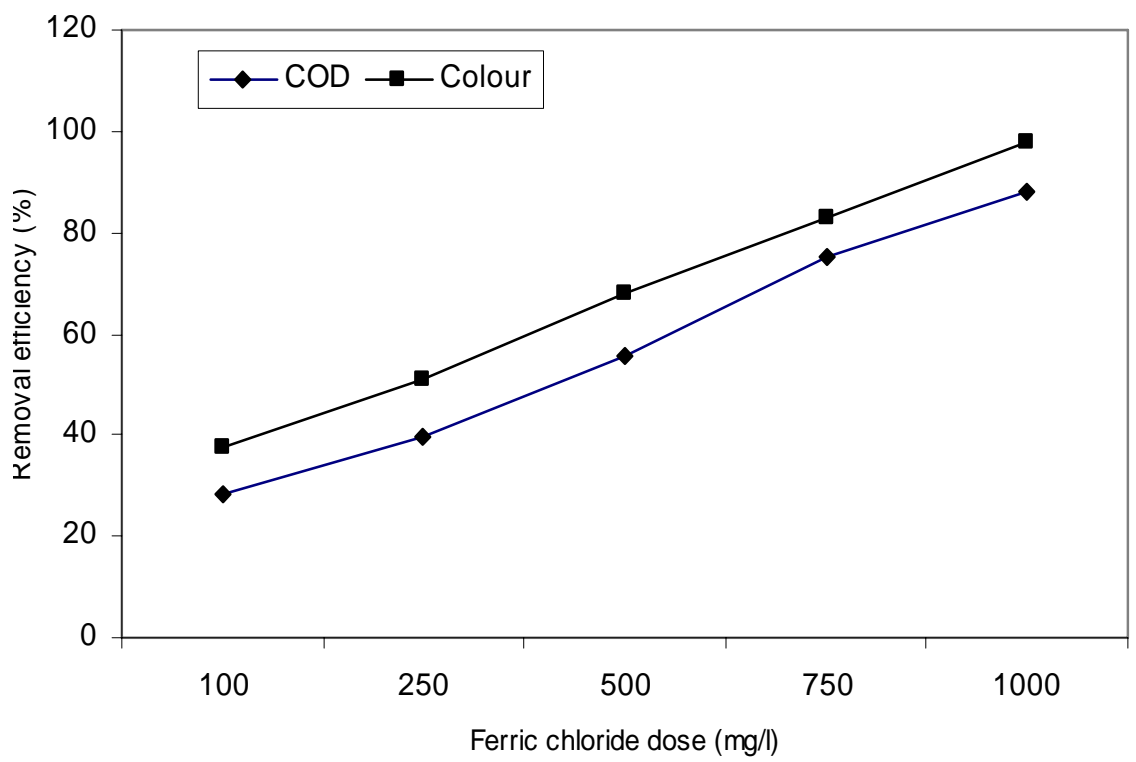

Fig. 4: Effect of different dosages of $\mathrm{FeCl}_{3}$ on the coagulation-Fenton process

Increasing the concentration of $\mathrm{FeCl}_{3}$ up to $1000 \mathrm{mg} / \mathrm{l}$ increases removal efficiency of $\mathrm{COD}$ and color. The reaction of the iron salt $\left(\mathrm{Fe}^{2+}\right.$ or $\left.\mathrm{Fe}^{3+}\right)$ with $\mathrm{H}_{2} \mathrm{O}_{2}$ in Fenton system produces hydroxyl radicals as shown in reaction (1):

$$
\mathrm{Fe}^{2+}+\mathrm{H}_{2} \mathrm{O}_{2} \longrightarrow \mathrm{Fe}^{3+}+\mathrm{OH}^{-}
$$

The produced $\mathrm{Fe}^{3+}$ can react with $\mathrm{H}_{2} \mathrm{O}_{2}$ to produce hydroperoxyl radical

$$
\mathrm{Fe}^{3+}+\mathrm{H}_{2} \mathrm{O}_{2} \longrightarrow \mathrm{Fe}^{2+}+\mathrm{H}_{2} \mathrm{O}+\mathrm{H}^{+}
$$

Lower doses of $\mathrm{FeCl}_{3}$ favor the reaction of the $\mathrm{Fe}^{2+}$ with the $\mathrm{H}_{2} \mathrm{O}_{2}$ to generate hydroxyl radicals $\mathrm{OH}$ that are more reactive than hydroperoxyl $\left(\mathrm{HO}_{2}^{-}\right)$radicals (reaction 1). These in turn favor removal efficiency of COD and color from the leachate. Higher doses of $\mathrm{FeCl}_{3}$, for a given $\left(\mathrm{H}_{2} \mathrm{O}_{2}\right)$ concentration, accelerates the rate of decomposition of the $\mathrm{H}_{2} \mathrm{O}_{2}$ by reaction (2) to produce hydroperoxyl radicals $\left(\mathrm{HO}_{2}\right)$ that are less reactive than $\mathrm{OH}^{*}$. Increase in the ferrous ions lead to an increase in the unused quantity of iron salts; which contributed to an increase in the total dissolved solids (TDS) content of the leachate. (Gogate and Pandit, 2004) Highest removal efficiencies of 88 and 98\% COD and color respectively were obtained with 1000 $\mathrm{mg} \mathrm{FeCl}_{3}$.

Conclusion: Coagulation-Fenton process was used to treat landfill leachate collected from Aboru sanitary landfill site (Lagos, Nigeria). Results of the experiments revealed the following: $1000 \mathrm{mgFeCl}_{3}$ reduces COD and color by 37 and $62 \%$ respectively. The $\mathrm{pH}$ range of 3-4 was found to be effective for the coagulation-Fenton process. Increasing dosage of $\mathrm{H}_{2} \mathrm{O}_{2}$ from 0.1 to $0.5 \mathrm{M}$ increases the enhancement of removal of contaminants. Higher dosage can act as scavengers for the generated hydroxyl radicals that are needed by ferryl ion to maintain Fenton's reaction. Temperature effect on the removal of COD from the leachate during Fenton's reaction process was negligible. $1000 \mathrm{mg} \mathrm{FeCl}_{3}$ enhances efficient removal of COD and color in the coagulation-Fenton process by 88 and $98 \%$ respectively. Increasing $\mathrm{FeCl}_{3}$ above $1500 \mathrm{mg}$ leads to an increase in the unused

Amuda, O S 
quantity of iron salt which contributes to increase in the TDS content of the landfill leachate.

Acknowledgement: The author acknowledged his student - Afolabi Akin-Martins who assisted during sampling and analyses.

\section{REFERENCES}

Amokrane, A; Comel, C; Veron, J; (1997). Landfill Leachates Pre-treatment by CoagulationFlocculation. Wat. Res 31 (11), 2775-2782.

Amoo, IA; Ajayi, OO; Ipinmoroti, KO; Amuda, OS; (2004). Performance Optimization of Coagulation/Flocculants in the Treatment of Effluent from Soap/Detergent Industry Proc. Int. Conf. Chemical Society of Nigeria. Ahonkhai S. I. (ed); Mindex Press, Benin City Nigeria. 415420.

APHA -AWWA -WEF; (1995). Standard methods for the Examination of water and wastewater $19^{\text {th }}$ ed. Washington, DC, U.S.A.

Bossmann, SH; Oliveros, E; Gob, S; Siegwart, SP; Dahlem, L. Payawan, S; (1998). New Evidence against Hydroxyl Radicals as Reactive Intermediates in the Thermal and Photochemically Enhanced Fenton Reaction. J. Phys. Chem. A 102,5542.

Gogate, PR; Pandit, AB; (2004). A Review of Imperative Technologies for Wastewater Treatment I: Oxidation Technologies at Ambient Conditions. Adv. Environ. Res. 8 (3/4), 501-551.

Kang, YW; Hwang, KY; (2000). Effects of Reaction Conditions on the Oxidation Efficiency in the Fenton Process. Water Res. 34, 2786-2793.

Kwon, BG; Lee, DS; Kang, N; Yoon, J; (1999). Characteristics of p-Chlorophenol Oxidation by Fenton’s Reagent. Water Res. 33, 2110-2115.

Lin, SH; Lo, CC; (1997). Fenton Process for Treatment of Desizing Wastewater. Water Res. 31, 2050-2056.
Lin, SH; Lin, CM; Lev, HG; (1999). Operating Characteristics and Kinetic Studies of Surfactant Wastewater Treatment by Fenton Oxidation Water Res. 33, 1735- 1745.

Marttinen, SK; Kettunen, RH; Sormunen, KM; Soimasuo, RM; Rintala, J; (2002). Screening of physical-chemical Methods for Removal of Organic Material, Nitrogen and Toxicity from Low Strength Landfill Leachates. Chemosphere. 46, 851-858.

Martinez, NS; Fernandez, JF; Segura, XF; Ferrer, AS; (2003). Pre - oxidation of an Extremely Polluted Industrial Wastewater by the Fenton's Reagent .J. Hazard. Mater. B101,315-322.

Peres, JA; Beltran de Heredia, J; Dominguez, JR; (2004). Integrated Fenton's reagent Coagulation Flocculation process for the Treatment of Cork processing Wastewater. J. Hazard. Mater. 107 (3), 115-121.

Perez, M; Torrades, F; Domenech, X; Peral, J; (2002. Fenton and photo - Fenton oxidation of textile effluents. Water Res. 36, 2703-2710.

Pignatello, JJ; Liu, D; Huston, P; (1999). Evidence for Additional Oxidant in the Photoassisted Fenton Reaction. Environ Sci. Technol. 33, 1832-1839.

Tatsi, AA.A; Zouboulis, AI; Matis, KA; Samaras, P; (2003). Coagulation-Flocculation Pretreatment of Sanitary Landfill Leachates. Chemosphere 53, 737-744.

Trebouet, D; Schlumpf, JP; Jaouen, P; Quemeneur, F; (2001). Stabilized Landfill Leachate Treatment by combined Physico-Chemical- Nanofiltration proceses. Wat. Res. 35 (12), 2935-2942.

Wang, ZP; Zhang, Z; Lin, YJ; Deng, NS; Tao, T; Zhuo, K; (2002). Landfill Leachate Treatment by a Coagulation-photooxidation process. J. Hazard. Mater. 95 (1/2), 153-159. 